\title{
Comparison of sulphur dioxide and metabisulphite airway reactivity in subjects with asthma
}

\author{
P I Field, M McClean, R Simmul, N Berend
}

\begin{abstract}
Background - In asthmatic subjects bronchoconstriction is induced by inhalation of the common food preservatives sulphur dioxide $\left(\mathrm{SO}_{2}\right)$ and metabisulphite (MBS). $\mathrm{SO}_{2}$ and $\mathrm{MBS}$ challenges share many similarities, but it is not known whether they are equivalent. In this study of subjects with mild clinical asthma equivalence was assessed by comparing $\mathrm{SO}_{2}$ and $\mathrm{MBS}$ reactivity by estimating the total dose of $\mathrm{SO}_{2}$ inhaled during $\mathrm{SO}_{2}$ and $\mathrm{MBS}$ challenges, and by calculating $\mathrm{SO}_{2}$ uptake during both challenges. In addition, as the MBS solutions inhaled were acidic and hyperosmolar, the effect of these factors on MBS responsiveness was investigated.
\end{abstract}

Methods - Fifteen subjects were challenged on separate days with doubling $(0.5$ to $8.0 \mathrm{ppm})$ concentrations of $\mathrm{SO}_{2}$ gas inhaled during three minute periods of isocapnic hyperventilation and MBS administered in doses ranging from 0.1 to $12.8 \mu \mathrm{mol}$ using the Wright protocol. On two other days $\mathrm{SO}_{2}$ and $\mathrm{MBS}$ challenges were preceded by a challenge with phosphate buffered saline (PBS) solutions of pH and osmolarity similar to MBS solutions. Response was measured as the dose or concentration causing a $20 \%$ fall in FEV $_{1}\left(\mathrm{PD}_{20}\right.$ or $\left.\mathrm{PC}_{20}\right)$.

Results - All subjects reacted to MBS and 14 responded to $\mathrm{SO}_{2}$. Geometric mean histamine $P_{20}$ was $1.61 \mu \mathrm{mol} \quad(95 \%$ confidence interval 0.72 to $3 \cdot 60$ ). MBS and $\mathrm{SO}_{2}$ airway responsiveness were not significantly related. Estimates of the mean concentration of $\mathrm{SO}_{2}$ inhaled during $\mathrm{SO}_{2}$ and $M B S$ challenges differed, as did estimates of the mean $\mathrm{SO}_{2}$ uptake during both challenges. $\mathrm{MBS}$ and $\mathrm{SO}_{2}$ reactivity were not affected by prior challenge with PBS solutions.

Conclusions - $\mathrm{SO}_{2}$ and $\mathrm{MBS}$ challenges are not comparable. MBS reactivity was not affected by the hyperosmolar, acidic nature of its solutions.

(Thorax 1994;49:250-256)

Sulphiting agents such as sodium metabisulphite (MBS) and sulphur dioxide $\left(\mathrm{SO}_{2}\right)$ are commonly used as food and wine preservatives. In subjects with asthma ingestion of foods and beverages containing these agents can provoke bronchoconstriction, ${ }^{1}$ but broncho- constriction develops more frequently following inhalation of either $\mathrm{SO}_{2}$ gas $^{2}$ or metabisulphite aerosols ${ }^{3}$ which are commonly used in the laboratory to assess sensitivity to sulphiting agents. Many characteristics of the airway responses to $\mathrm{SO}_{2}$ and $\mathrm{MBS}$ are similar, ${ }^{4}$ so the mechanism by which inhaled MBS provokes bronchoconstriction has been attributed to $\mathrm{SO}_{2}$ released from $\mathrm{MBS}$ aerosols, and $\mathrm{SO}_{2}$ and MBS challenges have been considered to be equivalent. However, the effect of inhaled MBS may not be solely due to liberated $\mathrm{SO}_{2}$. In solution MBS also converts to bisulphite, another potent bronchoconstricting stimulus, and MBS induced bronchoconstriction may be caused by the bisulphite ions in the aerosols acting alone, or together with generated $\mathrm{SO}_{2} .{ }^{5}$ Some of the mechanisms by which $\mathrm{SO}_{2}$ and MBS provoke bronchoconstriction appear to be similar, but there are also differences. Nedocomil sodium inhibits bronchoconstriction induced by both $\mathrm{SO}_{2}{ }^{6}$ and $\mathrm{MBS},{ }^{4}$ but while anticholinergic agents have no effect on the response to $\mathrm{MBS}^{7}$ in at least $30 \%$ of asthmatic subjects $\mathrm{SO}_{2}$ induced bronchoconstriction is cholinergically mediated. ${ }^{28}$

The aim of this study was to determine whether the bronchoconstrictions induced by inhalation of $\mathrm{SO}_{2}$ and MBS were similar. This was first examined by comparing the provocative concentration of $\mathrm{SO}_{2}$ and dose of $\mathrm{MBS}$ which caused FEV to fall by more than $20 \%$ from baseline. Secondly, to determine whether $\mathrm{SO}_{2}$ and $\mathrm{MBS}$ challenges were equivalent in terms of the amount of $\mathrm{SO}_{2}$ inhaled the concentration of $\mathrm{SO}_{2}$ delivered during an $\mathrm{SO}_{2}$ challenge, and the concentration released and inhaled during an MBS challenge, were compared. Thirdly, the uptake of $\mathrm{SO}_{2}$ gas during MBS and $\mathrm{SO}_{2}$ challenges was estimated and the values compared. Lastly, as the MBS challenge protocol used in this study involved dissolving it in acidic, hyperosmolar solutions, it was important to determine whether these properties of MBS solutions affected responses to MBS, and therefore the comparison between $\mathrm{MBS}$ and $\mathrm{SO}_{2}$ airway responses.

\section{Methods}

DOSE-RESPONSE STUDIES

Fifteen clinically stable subjects (seven women, eight men) aged 18-53 years were studied (table 1). Twelve subjects were atopic on skin prick testing and all were non-smokers. Four subjects were taking regular inhaled steroids (beclomethasone 400-1000 $\mathrm{gg}$ daily) and all used a $\beta_{2}$ agonist as required. Baseline 
Table 1 Anthropometric details, baseline forced expiratory volume in one second $\left(F E V_{l}\right)$ expressed as percentage of predicted value measured on the first study day, provoking concentration of sulphur dioxide $\left(\mathrm{SO}_{2}\right)$ and provoking doses of metabisulphite (MBS) and histamine that caused a $20 \%$ fall in FEV

\begin{tabular}{lllcccl}
\hline $\begin{array}{l}\text { Subject } \\
\text { no. }\end{array}$ & $\begin{array}{l}\text { Sex/Age } \\
\text { (years) }\end{array}$ & Treatment & $\begin{array}{l}\text { Baseline } \\
F E V, \\
(\% \text { pred })\end{array}$ & $\begin{array}{c}\mathrm{SO}_{2} \\
P C_{20} \\
(p p m)\end{array}$ & $\begin{array}{l}M B S \\
P D_{20} \\
(\mu m o l)\end{array}$ & $\begin{array}{l}\text { Histamine } \\
P D_{20} \\
(\mu m o l)\end{array}$ \\
\hline 1 & $\mathrm{~F} / 22$ & $\mathrm{~S}$ & 83 & $2 \cdot 9$ & $2 \cdot 5$ & $5 \cdot 6$ \\
2 & $\mathrm{M} / 31$ & $\mathrm{~S}, \mathrm{~B}$ & 80 & $2 \cdot 4$ & $1 \cdot 7$ & $0 \cdot 3$ \\
3 & $\mathrm{~F} / 29$ & $\mathrm{~S}$ & 90 & $2 \cdot 8$ & $3 \cdot 8$ & $0 \cdot 1$ \\
4 & $\mathrm{M} / 21$ & $\mathrm{~S}, \mathrm{~B}$ & 92 & $1 \cdot 0$ & $4 \cdot 5$ & $0 \cdot 6$ \\
5 & $\mathrm{~F} / 28$ & $\mathrm{~S}, \mathrm{~B}$ & 99 & $5 \cdot 8$ & $3 \cdot 2$ & $2 \cdot 1$ \\
6 & $\mathrm{~F} / 35$ & $\mathrm{~S}$ & 79 & $2 \cdot 8$ & $5 \cdot 6$ & $7 \cdot 4$ \\
7 & $\mathrm{~F} / 21$ & $\mathrm{~S}$ & 100 & $14 \cdot 5$ & $6 \cdot 1$ & $0 \cdot 8$ \\
8 & $\mathrm{M} / 30$ & $\mathrm{~S}$ & 112 & $5 \cdot 4$ & $6 \cdot 2$ & $3 \cdot 5$ \\
9 & $\mathrm{M} / 21$ & $\mathrm{~S}$ & 80 & $6 \cdot 2$ & $8 \cdot 6$ & $0 \cdot 5$ \\
10 & $\mathrm{~F} / 51$ & $\mathrm{~S}, \mathrm{~B}$ & 85 & $14 \cdot 5$ & $2 \cdot 7$ & $7 \cdot 8$ \\
11 & $\mathrm{M} / 53$ & $\mathrm{~S}$ & 86 & $6 \cdot 2$ & $6 \cdot 4$ & $1 \cdot 8$ \\
12 & $\mathrm{~F} / 18$ & $\mathrm{~S}$ & 100 & $23 \cdot 5$ & $4 \cdot 0$ & $2 \cdot 9$ \\
13 & $\mathrm{M} / 30$ & $\mathrm{~S}$ & 102 & $16 \cdot 0$ & $12 \cdot 0$ & $6 \cdot 2$ \\
14 & $\mathrm{M} / 32$ & $\mathrm{~S}$ & 102 & $17 \cdot 0$ & $8 \cdot 6$ & $0 \cdot 7$ \\
15 & $\mathrm{M} / 26$ & $\mathrm{~S}$ & 85 & $8 \cdot 0$ & $7 \cdot 9$ & $7 \cdot 2$ \\
Mean & 30 & & 91 & & & \\
Geometric mean & & & $6 \cdot 17$ & $4 \cdot 47$ & $1 \cdot 61$ \\
\hline
\end{tabular}

$\mathrm{S}=$ salbutamol; $\mathrm{B}=$ beclomethasone dipropionate. gas mixture, which were maintained at $65 \%$ relative humidity and $27^{\circ} \mathrm{C}$, were measured with a Novasina temperature and humidity probe (Novasina, Zurich, Switzerland) with the probe placed in the inspiratory port of the Hans Rudolf valve. The inspired $\mathrm{SO}_{2}$ concentration was continuously measured with an electrochemical cell $\mathrm{SO}_{2}$ analyser (Draeger, Sweden) through a port proximal to the Hans Rudolf valve. A Fleisch No. 3 pneumotachograph and differential pressure transducer $(P$ $\mathrm{K}$ Morgan, UK) measured air flow which was digitally integrated to obtain ventilation ( $\dot{\mathrm{V} E}$ ). A constant VE was maintained by subjects breathing in time to a metronome and inhaling a constant tidal volume, with each subject being cued by watching their respiration on a visual display unit. Subjects inhaled a constant tidal volume of either 1.0 or 1.51 depending on total lung capacity.

forced expiratory volume in one second $\left(\mathrm{FEV}_{1}\right)$ was above $75 \%$ of predicted values in all subjects. All subjects had a histamine $\mathrm{PD}_{20}$ of less than $7.8 \mu \mathrm{mol}$ with a geometric mean of $1.61 \mu \mathrm{mol}$ ( $95 \%$ CI 0.72 to 3.60). Aerosol bronchodilators were withheld for at least six hours before testing. Informed consent to the protocol, which was approved by the medical ethics review committee of the Royal North Shore Hospital, was obtained from all subjects.

Spirometric parameters were measured by a Vitalograph dry spirometer (Vitalograph, Buckingham, UK). During both $\mathrm{SO}_{2}$ and MBS challenges $\mathrm{FEV}_{1}$ was measured before challenge and at one and two minutes after each dose. Measurements were made in duplicate and if values differed by more than $100 \mathrm{ml}$ a third measurement was taken. The highest of two or three measurements was taken.

\section{Sulphur dioxide challenge}

Subjects were challenged with $\mathrm{SO}_{2}$ during sequential three minute periods of eucapnic hyperpnoea separated by three minutes. After measurement of baseline $\mathrm{FEV}_{1}$ subjects first inhaled a partially humidified air control, followed by doubling concentrations $(0.5,1.0$, $2 \cdot 0,4.0$, and $8.00 \mathrm{ppm}) \mathrm{SO}_{2}$. An additional $8.0 \mathrm{ppm} \mathrm{SO}_{2}$ was administered to three of the 15 subjects to enable measurement of a response to $\mathrm{SO}_{2}$. The challenge was stopped when $F E V_{1}$ fell by $20 \%$ or more of the control response, or the highest concentration was inhaled.

Sulphur dioxide (100\%) was delivered via a Nupro dual double pattern metering valve and $60 \mu \mathrm{m}$ filter to a stainless steel chamber where it was continually mixed with partially humidified air before being stored in a 1001 Seran bag (Aspec, Ann Arbor, Michigan, USA). End tidal carbon dioxide was maintained at normal resting levels during hyperpnoea by adding 4 $5 \%$ carbon dioxide to the bag gas mixture. Subjects inhaled the gas mixture using a noseclip via a two way Hans Rudolf valve. The air temperature and humidity of the inspired

\section{Metabisulphite challenge}

Metabisulphite challenges were administered with the protocol described by Wright et al. ${ }^{4}$ Sodium metabisulphite solutions were made up in phosphate buffered saline (PBS) in concentrations of $6.2,12.5,50$, and $100 \mathrm{mg} / \mathrm{ml}$. The doses of MBS administered were $0 \cdot 1,0 \cdot 2$, $0 \cdot 4,0.8,1 \cdot 6,3 \cdot 2,6 \cdot 4$, and $12.8 \mu \mathrm{mol}$. Aerosols were delivered with De Vilbiss No. 40 hand held nebulisers (DeVilbiss Corporation, Somerset, Pennsylvania, USA) and all challenges were performed within 30 minutes of preparing the solutions. After inhaling a control aerosol of PBS, increasing doses of MBS were inhaled at three minute intervals. The challenge ended when $\mathrm{FEV}_{1}$ fell by $20 \%$ or more from the control measurement, or when the maximal dose had been administered. The $\mathrm{pH}$ and osmolarity of the MBS solutions were 6.56 and $415 \mathrm{mosmol}$ in the $6.25 \mathrm{mg} / \mathrm{ml} \mathrm{solu}$ tion, 6.26 and $520 \mathrm{mosmol}$ in the $12.5 \mathrm{mg} / \mathrm{ml}$ solution, 5.43 and $1160 \mathrm{mosmol}$ in the $6.4 \mathrm{mg} /$ $\mathrm{ml}$ solution, and 4.95 and $1960 \mathrm{mosmol}$ in the $12 \cdot 8 \mathrm{mg} / \mathrm{ml}$ solution.

\section{$P B S$ and histamine challenges}

Phosphate buffered saline challenges involved inhalation of solutions of increasing osmolarity, $\mathrm{pH}$ and titratable acidity, equivalent to the MBS solutions, using the MBS challenge protocol described above. The osmolarity and $\mathrm{pH}$ of the MBS and control PBS solutions are shown in table 2 .

Histamine challenges were carried out as described by Yan and coworkers. ${ }^{9}$ Histamine

Table 2 Characteristics of metabisulphite (MBS) and equivalent phosphate buffered saline (PBS) solutions

\begin{tabular}{llc}
\hline Solutions & $p H$ & Osmolarity (mosmol) \\
\hline MBS 6.25 mg/ml & 6.56 & 415 \\
PBS equivalent & 6.78 & 382 \\
MBS $12.5 \mathrm{mg} / \mathrm{ml}$ & 6.26 & 520 \\
PBS equivalent & 6.24 & 510 \\
MBS $50 \mathrm{mg} / \mathrm{ml}$ & 5.43 & 1160 \\
PBS equivalent & 5.38 & 1150 \\
MBS $100 \mathrm{mg} / \mathrm{ml}$ & 4.95 & 1960 \\
PBS equivalent & 4.75 & 1990 \\
\hline
\end{tabular}


solutions $(3 \cdot 1,6 \cdot 0,25$, and $50 \mathrm{mg} / \mathrm{ml})$ were administered via DeVilbiss No. 40 hand held nebulisers in doses ranging from 0.03 to $7 \cdot 8 \mu \mathrm{mol}$ histamine. The test was stopped when there was a fall in $\mathrm{FEV}_{1}$ of $20 \%$ or more, or after $7.8 \mu \mathrm{mol}$ histamine had been administered.

\section{Test procedure}

Subjects attended the laboratory five times. At visit 1 they were evaluated by performing baseline pulmonary function, a histamine challenge test, and skin prick tests to common inhaled allergens including Dermatophagoides pteronyssinus, cat and dog dander, Alternaria and Aspergillus moulds, and rye, prairie and timothy grasses. At visit 2 an MBS challenge was performed immediately after a PBS challenge. At visits 3, 4, and 5 subjects were randomly challenged with $\mathrm{MBS}$ or $\mathrm{SO}_{2}$ or, on the other day, a PBS challenge was performed followed immediately by an $\mathrm{SO}_{2}$ challenge. Challenge with PBS solutions before MBS and $\mathrm{SO}_{2}$ challenges was performed to determine whether the acidic, hyperosmolar properties of the PBS solutions caused bronchoconstriction, and also whether these solutions potentiated the airway response to MBS. It was expected that a bronchoconstrictive effect due to the properties of the PBS solutions would be identified by challenges performed before both MBS and $\mathrm{SO}_{2}$. The administration of a PBS challenge before an $\mathrm{SO}_{2}$ challenge was included in order to determine whether PBS solutions potentiated the bronchoconstrictive response, as it was possible this would be missed when a PBS challenge preceded an MBS challenge which involved adminstration of MBS dissolved in the hyperosmolar, acidic PBS solutions.

STUDIES OF CONCENTRATION OF $\mathrm{SO}_{2}$ INHALED DURING $\mathrm{SO}_{2}$ AND MBS CHALLENGES

To calculate the concentration of $\mathrm{SO}_{2}$ inhaled during both challenges it was necessary to determine whether $\mathrm{SO}_{2}$ and $\mathrm{MBS}$ challenges were cumulative or non-cumulative in effect. Three subjects with controlled asthma were challenged with MBS on two consecutive days and on two other consecutive days $\mathrm{SO}_{2}$ challenges were performed. On the first day of a set of challenges an $\mathrm{SO}_{2}$ or MBS challenge, as described above, was performed. On the second day the final $\mathrm{SO}_{2}$ concentration or dose of MBS which caused a $20 \%$ fall in $\mathrm{FEV}_{1}$ on the first day was given.

\section{Measurement of $\mathrm{SO}_{2}$ gas produced by each $M B S$ solution}

The concentration of $\mathrm{SO}_{2}$ generated by each concentration of MBS was measured by squeezing one puff of an MBS solution into a three litre syringe. The concentration of $\mathrm{SO}_{2}$ was measured with an electrochemical $\mathrm{SO}_{2}$ analyser (Draeger, Sweden) and $\mathrm{SO}_{2}$ concentrations greater than $10 \mathrm{ppm}$ were diluted with air to obtain a measurement. Measurements were made on three separate occasions and each time the amount of $\mathrm{SO}_{2}$ released from each MBS solution was measured three times. Mean values were calculated.

Calculations to determine the concentration of $\mathrm{SO}_{2}$ gas inhaled during $\mathrm{SO}_{2}$ and $\mathrm{MBS}$ challenges

The concentration of $\mathrm{SO}_{2}$ delivered during inhalation of $\mathrm{SO}_{2}$ was calculated by multiplying the $\mathrm{SO}_{2}$ concentration (ppm) inhaled by the ventilation $(1 / \mathrm{min})$ maintained during inhalation by the duration of inhalation of $\mathrm{SO}_{2}$ (minutes). The amount of $\mathrm{SO}_{2}$ delivered during inhalation of a dose of MBS was estimated by multiplying the concentration of $\mathrm{SO}_{2}(\mathrm{ppm})$ released from the MBS solution by the number of inhalations involved in administering the dose of MBS.

\section{UPTAKE OF $\mathrm{SO}_{2}$ DURING $\mathrm{SO}_{2}$ AND MBS}

\section{CHALLENGES}

Experiments to estimate the in vivo uptake of $\mathrm{SO}_{2}$ gas with each dose of $\mathrm{MBS}$ and each concentration of $\mathrm{SO}_{2}$ were performed by three non-asthmatic, non-atopic subjects. After inhalation of a dose of MBS or concentration of $\mathrm{SO}_{2}$ subjects exhaled via a mouthpiece into a $750 \mathrm{ml}$ container in which the sample line and sample return line of an electrochemical $\mathrm{SO}_{2}$ analyser (Draeger, Sweden) were placed. Measurement of $\mathrm{SO}_{2}$ concentration was made immediately after exhalation. Measurement of the amount of $\mathrm{SO}_{2}$ exhaled following inhalation of a dose of MBS was made after each puff of an aerosol and after the final inhalation involved in administration of the dose. The amount of $\mathrm{SO}_{2}$ exhaled during $\mathrm{SO}_{2}$ challenges was measured after subjects inhaled $\mathrm{SO}_{2}$ for three minute periods of eucapnic hyperventilation. Three sets of measurements were recorded by each subject for each dose of MBS and each $\mathrm{SO}_{2}$ concentration. Mean values were calculated.

These in vivo measurements were used to calculate the uptake of $\mathrm{SO}_{2}$ which occurred during $\mathrm{SO}_{2}$ and $\mathrm{MBS}$ challenges. $\mathrm{SO}_{2}$ uptake was estimated by the following equation:

$$
\mathrm{SO}_{2} \text { uptake }=1-\frac{\left(\mathrm{SO}_{2} \text { concentration exhaled }\right)}{\left(\mathrm{SO}_{2} \text { concentration inhaled }\right)}
$$

in which $\mathrm{SO}_{2}$ concentration inhaled was the concentration either generated by MBS solution or administered during $\mathrm{SO}_{2}$ challenge, and unity represented total uptake.

To calculate $\mathrm{SO}_{2}$ uptake in each subject the estimate of the total concentration of $\mathrm{SO}_{2}$ inhaled by a subject was multiplied by the appropriate $\mathrm{SO}_{2}$ uptake fraction, as calculated above.

\section{ANALYSIS OF DATA}

A two way analysis of variance was used to determine if there were any differences in baseline $\mathrm{FEV}_{1}$ on each study day and the $\mathrm{FEV}_{1}$ measured before $\mathrm{SO}_{2}$ and $\mathrm{MBS}$ challenges on 
Table 3 Forced expiratory volume in one second ( $\left.F E V_{1}\right)$ in asthmatic subjects for metabisulphite (MBS) challenge and $M B S$ preceded by phosphate buffered saline (PBS) challenge (PMBS): baseline and after PBS challenge values

\begin{tabular}{|c|c|c|c|}
\hline \multirow[b]{2}{*}{ Subject no. } & \multirow{2}{*}{$\begin{array}{l}\text { MBS challenge FEV, }(l) \\
\text { Baseline }\end{array}$} & \multicolumn{2}{|c|}{ PMBS challenge $F E V_{1}(l)$} \\
\hline & & Baseline & After PBS \\
\hline $\begin{array}{r}1 \\
2 \\
3 \\
4 \\
5 \\
6 \\
7 \\
8 \\
9 \\
10 \\
11 \\
12 \\
13 \\
14 \\
15\end{array}$ & $\begin{array}{l}3.55 \\
3.35 \\
3.30 \\
4.35 \\
3.40 \\
2.50 \\
3.20 \\
4.20 \\
3.20 \\
2.00 \\
2.70 \\
3.75 \\
4.05 \\
3.90 \\
3.90\end{array}$ & $\begin{array}{l}3.50 \\
3.35 \\
3.35 \\
4.40 \\
3.30 \\
2.55 \\
3.20 \\
4.20 \\
3.10 \\
2.00 \\
2.80 \\
3.75 \\
4.05 \\
3.90 \\
3.85\end{array}$ & $\begin{array}{l}3.55 \\
3.40 \\
3.35 \\
4.45 \\
3.20 \\
2.50 \\
3.25 \\
4 \cdot 10 \\
3.05 \\
2.00 \\
2.75 \\
3.70 \\
4.00 \\
3.85 \\
3.85\end{array}$ \\
\hline $\begin{array}{l}\text { Mean } \\
\text { SD }\end{array}$ & $\begin{array}{l}3.42 \\
0.65\end{array}$ & $\begin{array}{l}3.42 \\
0.65\end{array}$ & $\begin{array}{l}3.40 \\
0.65\end{array}$ \\
\hline
\end{tabular}

those days when subjects were first challenged with PBS. The effect of eucapnic hyperventilation of humidified air on pulmonary function during $\mathrm{SO}_{2}$ challenges was evaluated by paired $t$ tests.

Dose-response curves were plotted for each challenge, showing the change in $\mathrm{FEV}_{1}$ against the log of the dose of MBS and against the log of the cumulative concentration of $\mathrm{SO}_{2}$ or cumulative dose of histamine. The $\mathrm{PD}_{20}$ or $\mathrm{PC}_{20}$ was obtained by linear interpolation. When the fall in $\mathrm{FEV}_{1}$ was less than $20 \%$ the maximum dose of MBS or maximum cumulative concentration of $\mathrm{SO}_{2}$ was recorded as the $\mathrm{PC}_{20}$ or $\mathrm{PD}_{20}$ value. The $\mathrm{PD}_{20}$ and $\mathrm{PC}_{20}$ values were $\log$ transformed and expressed as geometric mean. The differences in $\mathrm{PC}_{20}$ and $\mathrm{PD}_{20}$ resulting from challenges with $\mathrm{SO}_{2}$ and $\mathrm{SO}_{2}$ preceded by $\mathrm{PBS}\left(\mathrm{PSO}_{2}\right)$ and from challenges with MBS and MBS preceded by PBS (PMBS), were expressed as fold differences with $95 \%$ confidence intervals (CI).

The method of Bland and Altman ${ }^{10}$ was used to compare $\mathrm{PC}_{20}$ values obtained after challenges with $\mathrm{SO}_{2}$ and $\mathrm{PSO}_{2}$ challenges and to compare $\mathrm{PD}_{20}$ values recorded following MBS and PMBS challenges. The relation between $\mathrm{SO}_{2}$ and $\mathrm{MBS}$ airway reactivity was compared by linear regression. Paired $t$ tests were used to determine if there was any difference between

Table 4 Forced expiratory volume in one second $\left(F E V_{1}\right)$ in asthmatic subjects for sulphur dioxide $\left(\mathrm{SO}_{2}\right.$ ) challenge and $\mathrm{SO}_{2}$ preceded by phosphate buffered saline $(\mathrm{PBS})$ challenge $\left(\mathrm{PSO}_{2}\right):$ baseline, after $\mathrm{PBS}$ challenge, and after inhalation of humidified air control values

\begin{tabular}{|c|c|c|c|c|c|}
\hline \multirow[b]{2}{*}{ Subject no. } & \multicolumn{2}{|c|}{$\mathrm{SO}_{2}$ challenge $F E V_{1}(l)$} & \multicolumn{3}{|c|}{$\mathrm{PSO}_{2}$ challenge $\mathrm{FEV} V_{1}(l)$} \\
\hline & Baseline & After air & Baseline & After $P B S$ & After air \\
\hline $\begin{array}{r}1 \\
2 \\
3 \\
4 \\
5 \\
6 \\
7 \\
8 \\
9 \\
10 \\
11 \\
12 \\
13 \\
14 \\
15\end{array}$ & $\begin{array}{l}3.50 \\
3.35 \\
3.30 \\
4.45 \\
3.35 \\
2.50 \\
3.25 \\
3.95 \\
3.20 \\
2.10 \\
2.70 \\
3.70 \\
3.85 \\
3.85 \\
3.65\end{array}$ & $\begin{array}{l}3.45 \\
3.40 \\
3.35 \\
4.50 \\
3.40 \\
2.45 \\
3.15 \\
4.15 \\
3.20 \\
2.10 \\
2.70 \\
3.80 \\
3.90 \\
3.90 \\
3.60\end{array}$ & $\begin{array}{l}3.40 \\
3.30 \\
3.50 \\
4.50 \\
3.20 \\
2 \cdot 60 \\
3.00 \\
4.00 \\
3 \cdot 10 \\
2 \cdot 10 \\
2 \cdot 80 \\
3.70 \\
4.00 \\
3.80 \\
3.80\end{array}$ & $\begin{array}{l}3.35 \\
3.20 \\
3.50 \\
4.50 \\
3.30 \\
2.65 \\
3 \cdot 10 \\
4.00 \\
3.15 \\
2.15 \\
2.75 \\
3.70 \\
4.00 \\
3.80 \\
3.80\end{array}$ & $\begin{array}{l}3.35 \\
3.20 \\
3.55 \\
4.50 \\
3.20 \\
2.65 \\
3.00 \\
4.00 \\
3.15 \\
2.15 \\
2.70 \\
3.75 \\
4.15 \\
3.85 \\
3.80\end{array}$ \\
\hline $\begin{array}{l}\text { Mean } \\
\text { SD }\end{array}$ & $\begin{array}{l}3.38 \\
0.60\end{array}$ & $\begin{array}{l}3 \cdot 40 \\
0 \cdot 64\end{array}$ & $\begin{array}{l}3.39 \\
0 \cdot 62\end{array}$ & $\begin{array}{l}3 \cdot 40 \\
0 \cdot 60\end{array}$ & $\begin{array}{l}3 \cdot 40 \\
0.63\end{array}$ \\
\hline
\end{tabular}

the concentration of $\mathrm{SO}_{2}$ inhaled during $\mathrm{SO}_{2}$ and MBS challenges, and between the uptake of $\mathrm{SO}_{2}$ gas during $\mathrm{SO}_{2}$ and $\mathrm{MBS}$ challenges. The association between histamine and $\mathrm{SO}_{2}$, and between histamine and MBS, was assessed by linear regression. Significance was taken at the $5 \%$ level.

\section{Results}

$\mathrm{SO}_{2}$ AND MBS STUDIES

There was no significant difference between baseline mean (SD) $\mathrm{FEV}_{1}$ on the different study days (tables 3 and 4 ) and these values did not differ from the mean baseline $\mathrm{FEV}_{1}$ of 3.40 $(0.59) 1$ recorded before histamine challenge.

All subjects responded to inhalation of MBS during both MBS and PMBS challenges. Inhalation of acidic, hyperosmolar PBS had no significant effect on baseline pulmonary function (table 3). MBS $\mathrm{PD}_{20}$ values ranged from 1.7 to $12.0 \mu \mathrm{mol}$ with a geometric mean of $4.47 \mu \mathrm{mol}(95 \%$ CI 3.16 to $6 \cdot 31$ ) (table 1 ). PMBS $\mathrm{PD}_{20}$ values ranged from 1.3 to $12.0 \mu \mathrm{mol}$ with a geometric mean of $4.47 \mu \mathrm{mol}$ (95\% CI 3.07 to 6.50 ). The mean change between MBS and PMBS PD $_{20}$ of $0.99(95 \%$ CI 0.79 to 1.25 ) fold differences was not significant (fig 1).

One subject (no. 15) did not respond to inhalation of $\mathrm{SO}_{2}$, either during $\mathrm{SO}_{2}$ or $\mathrm{PSO}_{2}$ challenges. This subject was assigned a value of $23.5 \mathrm{ppm}$ for both challenges. There was no significant difference in mean $\mathrm{FEV}_{1}$ before and after inhalation of the humidified air control which preceded $\mathrm{SO}_{2}$ challenges on both study days (table 4), nor did the mean change in $\mathrm{FEV}_{1}$ after inhalation of humidified air differ significantly on the two days. On the $\mathrm{SO}_{2}$ study day the mean difference between prechallenge $\mathrm{FEV}_{1}$ and $\mathrm{FEV}_{1}$ measured after inhalation of the humidified control was 0.0231 (95\% CI -0.02 to 0.06$)$ compared with a mean difference of $-0.0031(95 \% \mathrm{CI}-0.04$ to 0.03$)$ measured on the $\mathrm{PSO}_{2}$ study day. The mean $\dot{\mathrm{VE}}$ recorded during $\mathrm{SO}_{2}$ challenges on $\mathrm{SO}_{2}$ and $\mathrm{PSO}_{2}$ challenge days of $40.6(12.34) 1 / \mathrm{min}$ and $40.8(10.46) \mathrm{l} / \mathrm{min}$, respectively, were similar.

Baseline $\mathrm{FEV}_{1}$ did not change significantly

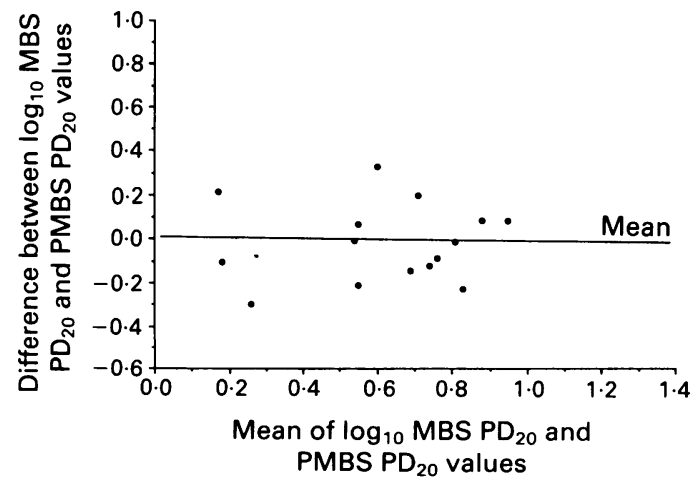

Figure 1 Relation in each subject ( $n=15$ ) between the mean of $\log _{10} P D_{20}$ values following challenge with metabisulphite (MBS) and challenge with phosphate buffered saline followed by $M B S$ (PMBS), and the difference between $\log _{10} P D_{20} M B S$ and $\log _{10} P D_{20}$ $P M B S . P D_{20} M B S$ is the dose of $M B S$ producing a $20 \%$ fall in FEV . 


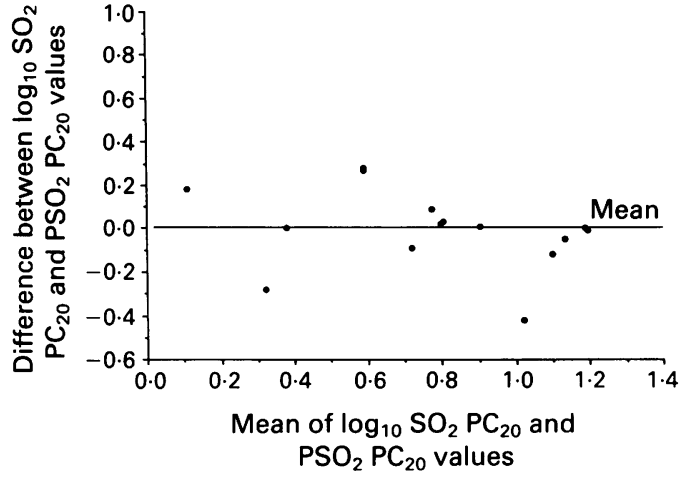

Figure 2 Relation in each subject $(n=15)$ between the mean of $\log _{10} P C_{20}$ values following challenge with sulphur dioxide $\left(\mathrm{SO}_{2}\right)$ and challenge with phosphate buffered saline followed by $\mathrm{SO}_{2}\left(\mathrm{PSO}_{2}\right)$, and the difference between $\log _{10} \mathrm{PC}_{20} \mathrm{SO}_{2}$ and $\log _{10} \mathrm{PC}_{20} \mathrm{PSO}_{2}$. $\mathrm{PC}_{20} \mathrm{SO}_{2}$ is the cumulative concentration of $\mathrm{SO}_{2}$ producing a $20 \%$ fall in $F E V$.

following challenge with PBS (table 4). Sulphur dioxide $\mathrm{PC}_{20}$ values ranged from 1.05 to $23.5 \mathrm{ppm}$ with a geometric mean of $6.17 \mathrm{ppm}$ (95\% CI 3.77 to 10.01 ) (table 1), and $\mathrm{PSO}_{2}$ $\mathrm{PC}_{20}$ values ranged from 1.5 to $23.5 \mathrm{ppm}$ with a geometric mean of $6.08 \mathrm{ppm}(95 \%$ CI 3.95 to 9.35). The mean change between $\mathrm{SO}_{2}$ and $\mathrm{PSO}_{2} \mathrm{PC}_{20}$ of $0.99(95 \%$ CI 0.78 to 1.25$)$ fold differences was not significant (fig 2).

The correlation between $\mathrm{MBS} \mathrm{PD}_{20}$ and $\mathrm{SO}_{2} \quad \mathrm{PC}_{20}$ was not significantly related $(r=0.42, \mathrm{p}>0.05)$ (fig 3). Responsiveness to histamine did not correlate significantly with responsiveness to either $\mathrm{SO}_{2}(r=0.35, \mathrm{p}>0.05$ (fig 4) or to MBS ( $r=0.47, \mathrm{p}>0.05$ ) (fig 5 ).

CONCENTRATION OF $\mathrm{SO}_{2}$ INHALED DURING $\mathrm{SO}_{2}$ AND MBS CHALLENGES

The effect of MBS did not appear to be cumulative. When three subjects inhaled increasing doses of MBS FEV 1 fell by a mean of $25 \cdot 6$ (4.3) $\%$ at the dose of MBS which caused $\mathrm{FEV}_{1}$ to fall by more than $20 \%$ from baseline. This change in $\mathrm{FEV}_{1}$ was similar to the mean change in $\mathrm{FEV}_{1}$ of $24.3(2 \cdot 3) \%$ which was recorded when only the final MBS dose was inhaled. In contrast, the effect of $\mathrm{SO}_{2}$ appeared cumulative. When three subjects inhaled $\mathrm{SO}_{2}$ the fall in $\mathrm{FEV}_{1}$ at the concentration of $\mathrm{SO}_{2}$ which caused $\mathrm{FEV}_{1}$ to fall by more than $20 \%$ from baseline was a mean of $22 \cdot 8(2 \cdot 6) \%$. This

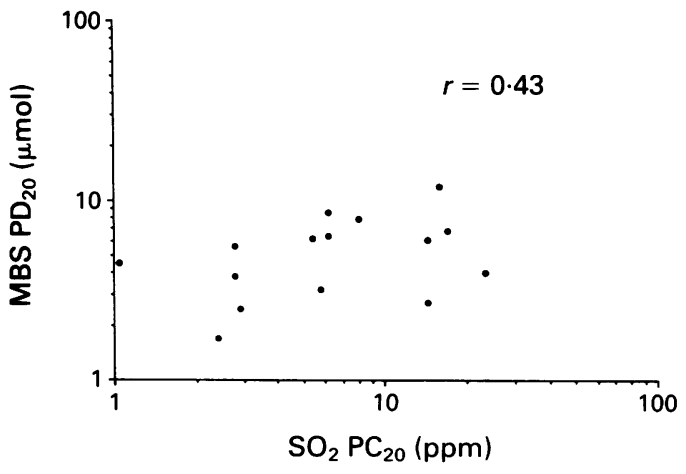

Figure 3 Relation between the $P C_{20}$ for sulphur dioxide $\left(\mathrm{SO}_{2}\right)$ (ppm) and the $P D_{20}$ for metabisulphite (MBS) ( $\mu \mathrm{mol}$ ) in 15 asthmatic subjects.

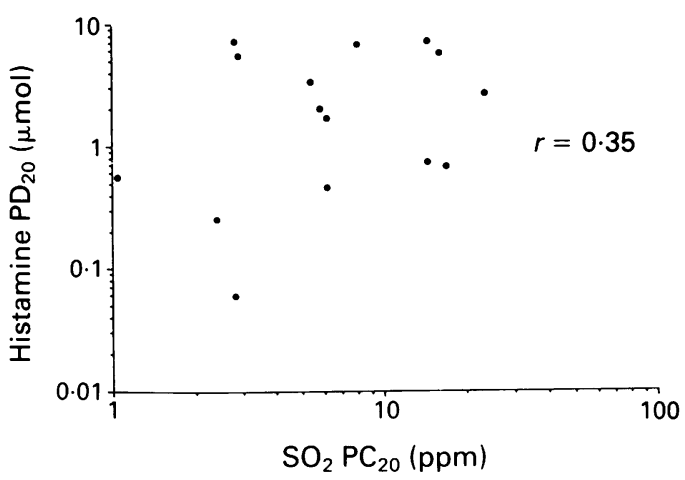

Figure 4 Relation between the $P C_{20}$ for sulphur dioxide $\left(\mathrm{SO}_{2}\right)(\mathrm{ppm})$ and the $P \mathrm{D}_{20}$ for histamine ( $\mu \mathrm{mol})$ in 15 asthmatic subjects.

change differed significantly from a mean fall in $\mathrm{FEV}_{1}$ of $9.3(0 \cdot 6) \%$ which occurred when only the final concentration of $\mathrm{SO}_{2}$ was inhaled.

The mean concentrations of $\mathrm{SO}_{2}$ released by the $6 \cdot 2,12 \cdot 5,50$, and $100 \mathrm{mg} / \mathrm{ml}$ solutions of MBS were $1.3(0 \cdot 14) \mathrm{ppm}$ (range 0.9-1.4), 1.92 $(0 \cdot 13)$ ppm (range $1 \cdot 8-2 \cdot 1), 18 \cdot 24(1 \cdot 65) \mathrm{ppm}$ (range 17-21.0), and 51.25 (3.89) ppm (range 48-54), respectively. As MBS did not act cumulatively, the concentration of $\mathrm{SO}_{2}$ inhaled by each subject during an MBS challenge was calculated using only the concentration of $\mathrm{SO}_{2}$ generated by the dose of MBS which caused $\mathrm{FEV}_{1}$ to fall by $20 \%$ from baseline. As $\mathrm{SO}_{2}$ challenges were cumulative, the concentration of $\mathrm{SO}_{2}$ inhaled by each subject was the sum of all the $\mathrm{SO}_{2}$ inhaled during the doses prior to and including the $\mathrm{SO}_{2}$ concentration which caused $\mathrm{FEV}_{1}$ to fall more than $20 \%$ from baseline.

Using these results it was estimated that, during MBS challenges, the total $\mathrm{SO}_{2}$ concentration delivered ranged from 45 to $381 \mathrm{ppm}$, with a mean of $168 \mathrm{ppm}$ (95\% CI 119 to 217 ). This was significantly different $(p<0.0001)$ from the total concentration of $\mathrm{SO}_{2}$ inhaled during $\mathrm{SO}_{2}$ challenges which ranged from 300 to $2325 \mathrm{ppm}$ with a mean of $957 \mathrm{ppm}$ ( $95 \% \mathrm{CI}$ 564 to 1350 ).

UPTAKE OF $\mathrm{SO}_{2}$ DURING $\mathrm{SO}_{2}$ AND MBS CHALLENGES

In vivo experiments confirmed that uptake of $\mathrm{SO}_{2}$ generated by each dose of MBS was almost complete. The $\mathrm{SO}_{2}$ concentration

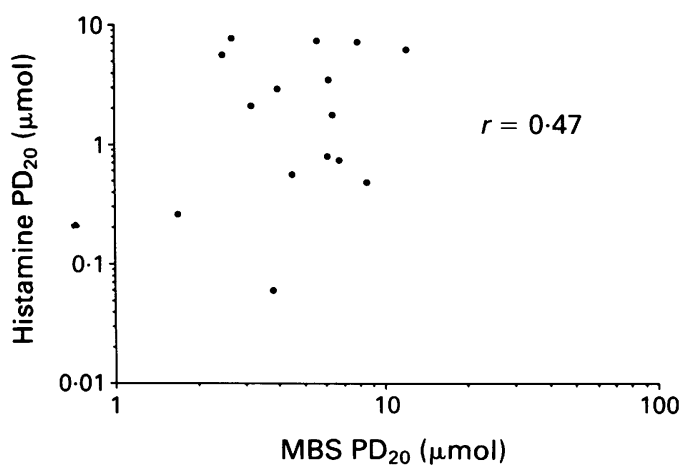

Figure 5 Relation between the $P D_{20}$ for metabisulphite ( $M B S$ ) ( $\mu \mathrm{mol}$ ) and the $P D_{20}$ for histamine ( $\mu \mathrm{mol}$ ). 
measured on exhalation after inhalation of each MBS dose was $0.5 \mathrm{ppm}$. When a dose of MBS involved more than one inhalation the concentration of $\mathrm{SO}_{2}$ in exhaled samples was the same, either when measured after each inhalation or when measured after the final inhalation. The estimated uptake of $\mathrm{SO}_{2}$ was $60 \%$ for a $0 \cdot 1 \mu \mathrm{mol}$ dose of MBS, $75 \%$ for $0 \cdot 2$, 0.4 , and $0.8 \mu \mathrm{mol}$ doses, and between $95 \%$ and $97 \%$ for $1.6,3.2,6.4$, and $12.8 \mu \mathrm{mol}$ doses of MBS. Uptake of $\mathrm{SO}_{2}$ was $80 \%$ for all $\mathrm{SO}_{2}$ concentrations.

When these results were used to estimate $\mathrm{SO}_{2}$ uptake it was calculated that, during MBS challenges, $\mathrm{SO}_{2}$ uptake ranged from 43 to $377 \mathrm{ppm}$ with a mean of $165 \mathrm{ppm}(95 \%$ CI 116 to 214$)$. This differed significantly $(\mathrm{p}<0.001)$ from the uptake of $\mathrm{SO}_{2}$ during $\mathrm{SO}_{2}$ challenges, when estimates ranged from 140 to $1860 \mathrm{ppm}$ with a mean of $765 \mathrm{ppm}$ (95\% CI 450 to 1080).

\section{Discussion}

Although inhalation of nebulised MBS is thought to provoke bronchoconstriction via generated $\mathrm{SO}_{2}$, no relation between $\mathrm{SO}_{2}$ and MBS airway responsiveness was found in this study. However, as all subjects recruited reacted to relatively high doses of both MBS and $\mathrm{SO}_{2}$, airway reactivity to $\mathrm{MBS}$ and $\mathrm{SO}_{2}$ may be related in subjects more sensitive to both agents. In addition, as a small number of subjects were studied, the failure to find a relation between $\mathrm{SO}_{2}$ and $\mathrm{MBS}$ responsiveness may have been due to a type II error.

The properties of aerosols which can cause airway narrowing in asthmatic subjects include the osmolarity, $\mathrm{pH}$, and titratable acidity. ${ }^{11} 12$ Bronchoconstriction is provoked by inhalation of hyperosmolar solutions ${ }^{12}$ and by inhalation of acidic solutions, with buffered acidic solutions inducing more severe airway narrowing than unbuffered solutions. ${ }^{11}$ The MBS solutions administered in this study were hyperosmolar and acidic and were also buffered by phosphate saline. However, when subjects inhaled PBS solutions of osmolarity, $\mathrm{pH}$, and titratable acidity equivalent to the MBS solutions, no bronchoconstriction was observed. These results are supported by the findings of Wright et $a l^{4}$ who partially investigated whether the properties of MBS solutions affected MBS responses. In their study five asthmatic subjects did not bronchoconstrict after challenge with saline solutions of osmolarity equivalent to the MBS solutions.

The acidic, hyperosmolar properties of the PBS solutions did not appear to potentiate airway responsiveness. There was no difference between $\mathrm{SO}_{2} \mathrm{PC}_{20}$ values obtained when an $\mathrm{SO}_{2}$ challenge was performed alone or preceded by a PBS challenge and, similarly, an initial PBS challenge did not affect MBS responsiveness. It is most likely that the properties of the solution in which MBS was dissolved did not affect the response to MBS because the quantity of aerosol adminstered was so small. In studies investigating the bronchoconstrictive potential of hyperosmolar aerosols $^{1213}$ and acidic aerosols ${ }^{11}$ the minimum volume inhaled has been $2 \mathrm{ml}$. The mean output of DeVilbiss nebulisers used in this study was $0.018 \mathrm{ml}$ per puff and, therefore, during an MBS challenge the greatest amount of aerosol administered was only $0 \cdot 14 \mathrm{ml}$.

The lack of a relation between $\mathrm{SO}_{2}$ and MBS airway responsiveness and the lower estimates of the amount of $\mathrm{SO}_{2}$ inhaled and absorbed during MBS challenges suggest that MBS induced bronchoconstriction is not solely due to generated $\mathrm{SO}_{2}$. When $\mathrm{MBS}$ is dissolved in solution it reacts chemically to form bisulphite and sulphite and $\mathrm{SO}_{2}$ is generated. These substances enter into equilibrium with each other, with more acidic solutions favouring generation of $\mathrm{SO}_{2}$. Bisulphite and $\mathrm{SO}_{2}$ are potent bronchoconstricting agents, whereas sulphite has only a weak effect. ${ }^{5}$ During MBS challenges aerosolised bisulphite and generated $\mathrm{SO}_{2}$ are highly reactive and it is likely that these bronchoconstricting stimuli continue to interact after inhalation. Bronchoconstriction could result from bisulphite ions deposited directly in the airways or formed locally from dissolved $\mathrm{SO}_{2}$ gas and from $\mathrm{SO}_{2}$, either inhaled or generated from bisulphite in the airways. In contrast, during $\mathrm{SO}_{2}$ challenges, when a constant concentration of $\mathrm{SO}_{2}$ is inhaled, $\mathrm{SO}_{2}$ is quickly absorbed in the aqueous environment of the airways. ${ }^{14}$ At the $\mathrm{pH}$ of human airways, which averages $6 \cdot 6,{ }^{15}$ it is likely that most of the inhaled $\mathrm{SO}_{2}$ rapidly converts to bisulphite. ${ }^{16}$ Thus, both $\mathrm{SO}_{2}$ and bisulphite probably play a part in $\mathrm{SO}_{2}$ and $\mathrm{MBS}$ induced bronchoconstriction, but the contribution of each stimulus to each challenge differs. Such a difference may underlie the lack of a relation between $\mathrm{SO}_{2}$ and MBS challenges.

Sulphur dioxide is almost completely absorbed when inhaled via the nose, ${ }^{14}$ but when inhaled via the mouth absorption of $\mathrm{SO}_{2}$ is altered by the concentration of $\mathrm{SO}_{2}$ administered and, more importantly, by the rate of administration. ${ }^{1418}$ When $1 \mathrm{ppm}$ and $10 \mathrm{ppm}$ $\mathrm{SO}_{2}$ were administered to rabbits $\mathrm{SO}_{2}$ absorption decreased from $99 \cdot 5 \%$ to $96.3 \%$, but following a tenfold increase in the rate of administration $\mathrm{SO}_{2}$ absorption fell to $66 \% .^{19}$ In our study it was estimated that $80 \%$ of each concentration of $\mathrm{SO}_{2}$ inhaled was absorbed. This uniform amount of absorption was most probably due to the rate of administration of $\mathrm{SO}_{2}$ which was inhaled at an average $\dot{\mathrm{VE}}$ of $40 \mathrm{l} / \mathrm{min}$. Factors which could influence absorption of $\mathrm{SO}_{2}$ or bisulphite ions generated during MBS challenges have not been investigated but, in our study, in vivo experiments indicated that more $\mathrm{SO}_{2}$ was absorbed at the higher MBS concentrations. One factor which could have affected our estimates of $\mathrm{SO}_{2}$ absorption in both $\mathrm{MBS}$ and $\mathrm{SO}_{2}$ challenges was desorption of $\mathrm{SO}_{2}$ from the mucosal surfaces of the upper airway. This begins immediately after ceasing exposure to $\mathrm{SO}_{2}$ and about $15 \%$ of the inspired concentration is desorbed over 30 minutes. ${ }^{1419}$ It is unlikely, however, that $\mathrm{SO}_{2}$ desorption significantly contributed to exhaled $\mathrm{SO}_{2}$ measurements performed in our study as $\mathrm{SO}_{2}$ concentrations were sampled over a matter of seconds. 
The lack of correlation between airway responsiveness to histamine and to either MBS or to $\mathrm{SO}_{2}$ has been observed in other studies. ${ }^{420}$ We also confirmed that MBS did not act cumulatively, which Wright et $a l^{4}$ had clearly demonstrated in 11 asthmatic subjects. However, increasing concentrations of $\mathrm{SO}_{2}$ were found to be cumulative in effect. This difference was studied in only a small number of asthmatic subjects because we had previously observed, in 15 asthmatic subjects using specific airway resistance to measure the airway response (unpublished data), that $\mathrm{SO}_{2}$ acted cumulatively when administered using the protocol described in this study. It is possible that this differing characteristic of MBS and $\mathrm{SO}_{2}$ responses relates to the duration of exposure to $\mathrm{SO}_{2}$ as, during $\mathrm{SO}_{2}$ challenges $\mathrm{SO}_{2}$ was inhaled continuously for three minute periods, whereas inhalation of MBS involved only three second breath holds.

In conclusion, $\mathrm{MBS}$ and $\mathrm{SO}_{2}$ airway responsiveness were not related in subjects with asthma. Although it is not clear whether bronchoconstriction provoked by inhalation of MBS is due to the effect of generated $\mathrm{SO}_{2}$ or bisulphite ions, ${ }^{5}$ the difference between the estimated amounts of $\mathrm{SO}_{2}$ inhaled during $\mathrm{SO}_{2}$ and $\mathrm{MBS}$ challenges, the differing estimates of $\mathrm{SO}_{2}$ uptake during both challenges, and the lack of a relation between $\mathrm{MBS}$ and $\mathrm{SO}_{2}$ airway reactivity all indicate that $\mathrm{MBS}$ induced bronchoconstriction involves mechanisms additional to the effect of generated $\mathrm{SO}_{2}$.

The authors wish to thank Jenny Peat, Senior Research Officer Department of Medicine, Sydney University for statistica advice. This research was funded by the Asthma Foundation of New South Wales.

1 Stevenson DD, Simon RA. Sensitivity to ingested metabisulphites in asthmatic subjects. $\mathcal{F}$ Allergy Clin Immuno 1981;68:26-32.

2 Sheppard D, Wong WS, Uechara CF, Nadel JA, Boushey HA. Lower threshold and greater bronchomotor respons- iveness of asthmatic subjects to sulfur dioxide. Am Rev Respir Dis 1980;122:873-8.

3 Schwartz HJ, Chester EH. Bronchospastic responses to aerosolised metabisulphite in asthmatic subjects: potential mechanisms and clinical implications. $\mathcal{f}$ Allergy Clin Immunol 1984;74:511-3.

4 Wright W, Zhang YG, Salome CM, Woolcock AJ. Effect of inhaled preservatives on asthmatic subjects. 1. Sodium metabisulfite. Am Rev Respir Dis 1990;141:1400-4.

5 Fine JM, Gordon T, Sheppard D. The roles of $\mathrm{pH}$ and ionic species in sulfur dioxide- and sulfite-induced bronionic species in sulfur dioxide- and sulfite-induced bron-
choconstriction. Am Rev Respir Dis 1987;136:1122-6.

6 Dixon CMS, Fuller RW, Barnes PJ. Effect of nedocromil sodium on sulphur dioxide induced bronchoconstriction Thorax 1987;42:462-5.

7 Nichol GM, Nix A, Chung KF, Barnes PJ. Characterisation of bronchoconstrictor responses to sodium metabisulphite aerosol in atopic subjects with and without asthma. Thorax 1989;44:1009-14.

8 Eschenbacher WL, Bethel RA, Boushey HA, Sheppard D. Morphine sulfate inhibits bronchoconstriction in subjects with mild asthma whose responses are inhibited by atropine. Am Rev Respir Dis 1984;130:363-7.

9 Yan K, Salome CM, Woolcock AJ. Rapid method for measurement of bronchial reactivity. Thorax 1983; 38:760-5.

10 Bland JM, Altman DG. Statistical methods for assessing agreement between two methods of clinical measurement. Lancet 1986;i:307-10.

11 Fine JM, Gordon T, Thompson JE, Sheppard DS. The role of titratable acidity in acid aerosol-induced bronchoconstriction. Am Rev Respir Dis 1987;135:826-30.

12 Schoeffel RE, Anderson SD, Altounyan REC. Bronchial hyperreactivity in response to inhalation of ultrasonically nebulized solutions of distilled water and saline. $B M F$ 1981;283:1285-7.

13 Bascom R, Bleecker ER. Bronchoconstriction induced by distilled water. Sensitivity in asthmatics and relationship to exercise-induced bronchospasm. Am Rev Respir Dis to exercise-induced

14 Speizer FE, Frank NR. The uptake and release of $\mathrm{SO}_{2}$ by the human nose. Arch Environ Health 1966;12:725-8.

15 Bodem CR, Lampton LM, Miller DP, Tarka EF, Everet ED. Endobronchial pH. Am Rev Respir Dis 1983;127:3944.

16 Petering DH, Shih NT. Biochemistry of bisulfite-sulfur dioxide. Environ Res 1975;9:55-65.

17 Zuazaga DC, Steinacher A, del Castillo J. The role of sulfhydryl and disulfide groups of membrane proteins in electrical and chemical transmission. Health $\mathrm{Sc}_{\mathrm{i}} \mathrm{f}$ 1985;3:125.

18 Dalhamn T, Strandberg L. Acute effects of sulfur dioxide on the rate of ciliary beat in the trachea of rabbits, in vivo, and in vitro, with studies on the absorptional capacity of and in vitro, with studies on the absorptional capacity of

19 Frank NR, Yoder RE, Brain JD, Yokoyama E. SO ${ }_{2}^{35} \mathrm{~S}$ rank NR, Yoder RE, Brain JD, Yokoyama E. $\mathrm{SO}_{2}$ ( ${ }^{35} \mathrm{~S}$
labeled) absorption by the nose and mouth under conditions of varying concentration and flow. Arch Environ Health 1969;18:315-22.

20 Delhory J, Simmul R, Castle WD, Allen DH. The relationship of inhaled sulfur dioxide reactivity to ingested metabisulfite sensitivity in patients with asthma. $A m$ Rev Respir Dis 1984;130:1027-32. 